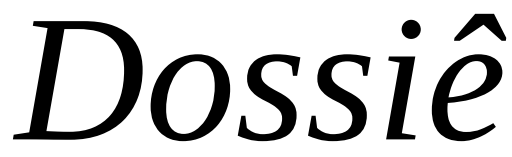

Educação a distância 



\section{Pensando a educação a distância a partir de lições aprendidas com Foucault}

\section{Thinking distance learning from the lessons learned from Foucault}

\section{Karla Saraiva * \\ Universidade Luterana do Brasil}

Resumo: O objetivo deste artigo é mostrar que a educação contemporânea e, em especial, a educação a distância, está sendo pensada para dar continuidade à proposta moderna de utilizar a educação como forma de governar as condutas e moralizar os indivíduos, colocando-se em estreita relação com os sistemas produtivos, ainda que apelando para outras estratégias e visando a produção de um outro sujeito moral. As análises são desenvolvidas a partir de um quadro conceitual de referencial foucaultiano, utilizando como material empírico um conjunto de artigos acadêmicos publicados em periódicos nacionais. $\mathrm{O}$ artigo mostra que na Contemporaneidade a moralização pensada para orientar a educação se torna mais sutil e mais abrangente, para reduzir possíveis resistências e atravessar o campo educacional em toda sua extensão, considerando-se a educação a distância um caso de particular interesse.

Palavras-chave: Educação a distância. Educação contemporânea. Subjetividade.

\begin{abstract}
The aim of this paper is to show that contemporary education and, in particular, distance education are conceived to continue the modern proposal to use education as a way to govern the conduct and moralizing individuals, standing in close relationship with productive systems, even appealing to other strategies and focusing on the production of another moral subject. The analysis is developed from a Foucauldian conceptual framework using as empirical data a set of academic papers published in Brazilian journals. The article demonstrates that in Contemporary the moralization conceived to guide education becomes more subtle and more comprehensive, trying to reduce possible resistance and crossing the field of education in all its extension, considering distance education a case of particular interest.
\end{abstract}

Key-words: Distance learning. Contemporary education. Subjectivity.

Como leitora de Foucault, aprendi com ele muitas e belas (algumas vezes, duras) lições. Todas muito proveitosas para minhas pesquisas no campo da Educação, especialmente para as análises que venho desenvolvendo a propósito da emergência e proliferação da educação a distância $(\mathrm{EaD})$ via internet. Neste artigo, mostro como as transformações sociais que estão em curso desde o final do século XX se encontram tramadas com transformações no campo educacional, constituindo uma das condições para a consolidação da EaD mediada por ambientes digitais.
* Doutora em Educação. E-mail: <karlasaraiva@ via-rs.net $>$ 
Inicio o artigo apresentando algumas das lições que recebi de Foucault que tornaram possível as análises que faço. Essas lições proporcionaram mais do que um arcabouço conceitual, o que já não seria pouco. Proporcionaram, principalmente, um modo diferente de problematizar as práticas ligadas à $\mathrm{EaD}$, produzindo estranhamentos ao que me era familiar. A seguir, apresento um breve comentário sobre a emergência da escola moderna e sua relação com os sistemas produtivos, tomando ambos como elos que interligam os modos de significar espaço e tempo e os processos de subjetivação. Prossigo mostrando os deslocamentos que se operam na Contemporaneidade no modo de perceber o espaço e o tempo e nos processos de subjetivação a partir de seus efeitos tanto no sistema educacional quanto no sistema produtivo. Por fim, mostro como essas transformações contribuem para o reconhecimento e para a consolidação da EaD.

\section{Das lições aprendidas com Foucault}

Talvez alguns possam estar se perguntando em que a obra de Foucault contribui para analisar a EaD com suporte on-line. Afinal, ele foi um autor dedicado a analisar principalmente a sociedade moderna, retornando até os gregos nos seus últimos escritos. Mesmo suas análises de acontecimentos mais contemporâneos, que seria o caso das suas investigações acerca do neoliberalismo, apresentadas no curso Segurança, território, população (FOUCAULT, 2006), à primeira vista não teriam conexão com esse objeto.

Entretanto, entendo que sua contribuição principal não reside nas temáticas que desenvolveu, mas nas ferramentas que construiu e generosamente deixou espalhadas em seus livros, artigos, entrevistas e cursos, permitindo que cada um recolhesse aquelas que desejasse, utilizando-as do modo que julgasse mais apropriado. E é com essas ferramentas que venho forjando um olhar diferenciado sobre as práticas da educação via internet. Embora seja impossível apontar todas as ferramentas que tomei da caixa de Foucault, algumas foram notadamente importantes para desenvolver o que apresento posteriormente.

Uma primeira lição, que foi útil e importante para todas as análises que venho fazendo, seria que a verdade existe, porém não está fundada na transcendência. É constituída neste mundo, por meio das práticas e atravessada por relações de poder (FOUCAULT, 2000). O que importa, então, não é perguntar se um determinado enunciado é verdadeiro, mas como se constituiu a noção do que seja verdadeiro, bem como seus efeitos. Compreender como se produziram os regimes de verdade permite que se pense como modificá-los, estratégias para deslocá-los e, eventualmente, maneiras de apagá-los. E é a partir dessa noção de verdades inventadas, datadas e contingentes que olho para meu material de pesquisa. 
Mas seriam as ferramentas foucaultianas ainda suficientes para empreender uma análise no campo da Educação na Contemporaneidade? Aqui entra uma segunda lição de Foucault. Certa feita, em uma entrevista, o filósofo declarou que gostaria que seus livros funcionassem como fogos de artifícios, que se carbonizam após o uso (POL-DROIT, 2006). Ou seja, ele não pretendia que seus livros fossem métodos a seguir, que encerrassem uma mensagem bem endereçada ou que fornecessem um sistema completo de pensamento. Seus livros deveriam explodir, encher o espaço, numa breve e fulgurante demonstração de sua potência. Foucault não queria seguidores, não pretendia ser exemplo. Era o "filósofo mascarado" (FOUCAULT, 2005), que não queria ser reconhecido, que se negava a tornar-se um ícone pop, que desejava ser deixado para trás. Foucault parecia compartilhar com Nietzsche (1995, p.20) a idéia de que "retribui-se mal a um mestre, continuando-se sempre apenas aluno". Ou, conforme Veiga-Neto (2003), Foucault nos incita a sermos infielmente fiéis a seu pensamento. Com isso, tenho a liberdade de inserir na caixa de ferramentas de que me sirvo utensílios que foram forjados por outros e que recolhi ao longo de meus estudos e pesquisas. Sem deixar de assistir à queima de fogos que Foucault proporciona.

Também com Foucault, aprendi a realizar análises externas dos regimes de verdade, tomar os textos como se fossem monumentos e buscar compreender sua relação com outros elementos que o cercam. Aprendi que para examinar uma determinada prática, numa perspectiva externalista, é necessário dirigir o olhar não para ela mesma, mas para aquilo que a cerca. E não apenas o que a cerca em um determinado momento, como também os a prioris históricos que permitiram sua emergência. E foi assim que procedi para analisar as verdades que estão sendo produzidas sobre a educação a distância com suporte de ambientes web.

Esses são alguns dos pressupostos gerais que assumi para minha pesquisa e que tomei das lições que aprendi com Foucault. Mas ainda outros pontos de suas lições colaboraram para que eu realizasse este trabalho. Seus escritos sobre as sociedades disciplinares modernas e suas instituições, em especial a escola, vêm servindo como ponto de partida para inúmeras pesquisas, artigos e livros no campo da Educação. Também eu tirei proveito tanto das ideias de Foucault quanto de seus comentaristas nessa temática. Uso esses estudos sobre a escola moderna como ponto de partida, para, depois, deixando, talvez, Foucault um pouco para trás, dedicar-me a pensar a Contemporaneidade.

Apresento na sequência deste artigo alguns entrelaçamentos entre educação, sistema produtivo e organização social na Modernidade e na Contemporaneidade, tomando os sistemas educativos como uma estratégia de governamento ${ }^{1}$, ou seja, uma estratégia de condução das condutas, que visa produzir sujeitos bem inseridos na organização social de seu tempo.

${ }^{1}$ Seguindo VeigaNeto (2002), uso o termo governamento para diferenciar da instituição Governo. 
Finalizo com uma breve análise das práticas de educação a distância, mostrando sua inserção na racionalidade educacional contemporânea.

\section{Escola e Modernidade}

Entre inúmeros elementos que tornaram possível a emergência da Modernidade, entendida como uma forma de ser e estar no mundo muito mais do que como um período histórico, destaco aqui as transformações nos significados e usos espaço-temporais. Na Idade Média, tempo e espaço eram pouco diferenciados, estando intrinsecamente imbricados. O espaço era fragmentado, dividido em diversos mundos, sendo a principal divisão a cisão entre um mundo do corpo e um mundo da alma, sendo que o segundo era considerado como aquele onde estaria a realidade primária da vida. O tempo ainda era uma noção remota e subjetiva, extremamente ligada aos ritmos da vida. Era um tempo cíclico e regido pelo divino.

A ciência iluminista promove a separação do tempo e do espaço, que passam a ser entendidos como independentes um do outro. O tempo toma uma forma objetiva e linear. O espaço perde sua fragmentação em diferentes mundos, passando a ser compreendido como infinito e homogêneo. Ambos passam a ser percebidos como objetivos, passíveis de serem mensurados e fracionados (SARAIVA, 2010).

Esses significados espaço-temporais que acabaram por prevalecer na sociedade moderna tornaram possível o surgimento daquilo que Foucault (1999) denominou de disciplina, no final do século XVII. Espaço e tempo mensuráveis e administráveis foram condições necessárias para a invenção da grade de horários e do quadriculamento espacial, dois dos principais instrumentos do poder disciplinar. Por meio da vigilância e utilizando como instrumentos o exame e a sanção, a disciplina tem por finalidade tornar o corpo útil e dócil. Essa modalidade de exercício de poder organizou as formas predominantes de escolarização e do sistema produtivo na Modernidade. Desde a Modernidade, escola e trabalho estão imbricados entre si, sendo o poder disciplinar possivelmente o principal elo entre ambos.

A escola moderna, organizada a partir de estratégias disciplinares, participa, desde o final do século XVII, da infância de um número crescente de sujeitos, colaborando na disciplinarização dos corpos desde seus primeiros anos de vida. Segundo Kant (1996, p.13, grifos meus), as crianças devem ir à escola antes de tudo para "que aí se acostumem a ficar sentadas tranquilamente e a obedecer pontualmente àquilo que lhes é mandado”. Aprender a cultura era apenas um aspecto secundário, pois isso poderia se dar fora da escola. A função moralizadora ${ }^{2}$ foi marcante na escola da Modernidade. No século XIX, o professor da escola primária não detém "tanto um saber, mas técnicas de domesticação, métodos para condicionar e manter a ordem; não transmite tanto conhecimento, mas uma moral” (VARELA; ALVAREZ-URIA, 1992, p.82).
${ }^{2}$ Para Foucault (2001a, p.26), moral é "um conjunto de valores e regras de ação propostas aos indivíduos”. Ou seja, toda forma de prescrição de como deve ser ou agir um indivíduo se constitui numa regra moral. 
A escola moderna funcionou como uma das principais condições que tornaram possível o estabelecimento do capitalismo industrial. Observe-se, entretanto, que o capitalismo não inventou o poder disciplinar ou a instituição escolar com suas pedagogias disciplinares. Antes, se apropriou de algo que deu sustentação ao seu estabelecimento, retomando e aperfeiçoando a escola para seus fins. A indústria moderna era organizada de modo rígido, dividindo o trabalho em tarefas simples. Cada operário estava encarregado de uma tarefa e dificilmente conhecia o processo todo. Para o exercício de sua função, não eram necessidades habilidades muito especiais: apenas um corpo treinado, capaz de realizar movimentos repetitivos com precisão e rapidez. No trabalho fabril, o mais importante não eram os conhecimentos escolares, mas um determinado comportamento muito semelhante àquele que Kant considerava que a escola deveria ensinar: obedecer ordens e manter-se em seu posto de trabalho.

Nesse cenário, a escola constituiu-se em uma instituição de grande relevância para a organização social, pois garantia a mão-de-obra para o sistema fabril, provendo corpos já docilizados, capazes de se adaptarem ao trabalho industrial com facilidade, e minimizando os riscos de distúrbios sociais. Os movimentos em prol da escola pública obrigatória no século XIX sinalizam o reconhecimento de sua importância para a domesticação das classes populares, transformando desordeiros em operários.

É possível dizer que a escola pública obrigatória foi engendrada por uma nova modalidade de poder que surge um século após o poder disciplinar, denominado por Foucault (2002) de biopoder. Ele não vai tomar o lugar do poder disciplinar, pelo contrário, mas o retoma e reinsere num sistema mais abrangente. O biopoder, que se exerce sobre o corpoespécie da população, concebeu a escola pública como um sistema capaz de contribuir na organização da sociedade, produzindo uma massa de trabalhadores e reduzindo o número de delinquentes. Ou seja, a escola funcionaria como uma estratégia para maximizar a força produtiva e minimizar a resistência política.

Contudo, se boa parte das crianças estava sendo docilizada nos bancos escolares, ainda havia muitos que não se adaptavam e escapavam da escola. A infância dita anormal, constituída majoritariamente por crianças de classes populares, cuja vida menos regrada dificultava seu ajuste às normas escolares, necessitava ser sequestrada a partir de outras estratégias. Entre o final do século XIX e o início do XX, surge a chamada Escola Nova, em que se destacam nomes como Dewey, Decroly, Montessori, entre outros. Embora os métodos propostos pelos diversos autores, chamados por Varela (1996) de pedagogias corretivas, difiram significativamente entre si, guardam como semelhança a proposição de usos espaço-temporais mais flexíveis e individualizados do que as pedagogias disciplinares e uma certa ênfase nos interesses e na autonomia dos indivíduos. Muitas dessas 
propostas surgiram voltadas para os chamados anormais e foram, gradativamente, sendo estendidas para toda a infância.

A preocupação com os anormais e a reorganização do uso espaçotemporal nas salas de aula surgem mais ou menos no mesmo período em que se percebe uma incipiente transformação nos significados espaçotemporais modernos. A objetividade cartesiana com que eram representados começa a mostrar algumas rachaduras, sinalizadas pelos trabalhos de alguns cientistas, em especial pela Teoria da Relatividade de Einstein, bem como por representações na literatura e nas artes plásticas (SARAIVA, 2010), como o cubismo.

Ainda que as pedagogias chamadas corretivas, relacionadas com os teóricos da Escola Nova, e psicológicas, com destaque para as obras de Piaget e Vigotsky (VARELA, 1996), estivessem sendo inventadas já no início do século XX, sua propagação acontecerá com mais força no último quarto do século, num processo quase simultâneo com as transformações nos processos produtivos e nas formas de trabalho. As transformações das concepções acerca da Educação e das formas de produção seriam fruto de uma mesma racionalidade contemporânea e estariam implicadas com as transformações no modo de significar e utilizar o espaço e o tempo.

\section{Escola e Contemporaneidade}

Conforme já apontado na seção anterior, entre o final do século XIX e início do século XX, apareceram as primeiras fissuras nos significados espaço-temporais modernos. Essas transformações tornaram-se marcantes no último quarto do século XX. Um vertiginoso aumento da velocidade de transporte de pessoas, objetos e informações acentua aquilo que Harvey (2001) chamou de compressão espaço-temporal. A noção de tempo e espaço como elementos independentes perde força, sendo que o espaço se desvaloriza em favor da velocidade. O que conta como poder já não é tanto a posse de pesados imóveis, ou seja, ter a posse de parte do espaço, mas a mobilidade e a capacidade de evadir-se. Romper as amarras com o território, com os sujeitos, com a própria subjetividade: desterritorializar-se. Potencializar a aptidão para alcançar antes os novos lugares e, se possível, criá-los: lugarização (VEIGA-NETO, 2002a). Volatilidade e flexibilidade são palavras da nova ordem.

Essa transformação dos significados e usos do espaço-tempo, que se acentua a partir do final do século XX, é uma das condições imbricadas com a transformação do sistema produtivo e da organização social, de modo geral. A partir da década de 70, emergem os sistemas pós-fordistas, deixando de lado as linhas de montagens rígidas, com pouca capacidade de adaptação, concebidas para a produção em massa. Em seu lugar, a indústria busca soluções para tornar-se mais leve e flexível, capaz de introduzir 
mudanças rápidas na produção e de customizar seus produtos. O capitalismo industrial começa a se converter em capitalismo cognitivo (GALVÃO; SILVA; COCCO, 2003), sistema que não prioriza a fabricação seriada de produtos, mas a produção de novas ideias e conhecimentos. $\mathrm{O}$ trabalho fabril começa, então, a perder importância, havendo uma valorização daquilo que alguns autores chamam de trabalho imaterial ${ }^{3}$. Segundo Hardt e Negri (2005, p.149), o trabalho imaterial "cria produtos imateriais, como o conhecimento, a informação, a comunicação, uma relação ou uma reação emocional”. Para esses autores, essa modalidade de trabalho é privilegiada na Contemporaneidade não por ela ser a que ocupa o maior número de pessoas, mas por exercer um poder de transformação sobre as outras modalidades, inclusive a atividade industrial e a agricultura, servindo como um novo modelo de trabalho.

Todas essas transformações apontam para um declínio da chamada sociedade disciplinar. Em 1978, o próprio Foucault (2001, p.532) já falava no declínio da disciplina: "Existe um número cada vez maior de categorias de pessoas que não estão absorvidas pela disciplina, o que nos obriga a pensar no desenvolvimento de uma sociedade sem disciplina”. De acordo com Deleuze (1992), estaríamos hoje nas sociedades de controles, "que funcionam não mais por confinamento, mas por controle contínuo e comunicação instantânea”, em que as normas disciplinares rígidas são substituídas por outras mais flexíveis e em permanente reconfiguração. Nessa nova ordem, parece-me que acontece uma expansão do biopoder, que se torna cada vez mais pervasivo e que busca fazer com que cada um passe a cuidar de si. Segundo Hardt e Negri (2002), na Contemporaneidade o biopoder recobre todo o tecido social.

O sistema educacional também tem sentido os efeitos do declínio do poder disciplinar. Parece-me que esses efeitos chegam aí por duas vias que, embora distintas, estão intrinsecamente interligadas. Em primeiro lugar, por meio dos próprios alunos que parecem tornar cada vez menos possível seu enquadramento nas normas disciplinares. Conforme diversos autores ${ }^{4}$ já discutiram, crianças e jovens hoje estão inseridos em um mundo de estímulos diversos e simultâneos, que os convocam a uma atividade e uma interatividade permanente. Seja por meio da TV, dos múltiplos sites da internet, dos jogos eletrônicos, dos celulares de incontáveis funções, esses sujeitos experimentam uma vida que parece em tudo contrariar os princípios disciplinares. Essas vivências concorrem com a escola e produzem representações e usos espaço-temporais que fazem com que o poder disciplinar perca sua eficácia. A disciplina entra em choque com outros dispositivos, fazendo com que se perceba uma escola progressivamente desencaixada. A dificuldade em disciplinar os corpos por parte daquela que tem sido a instituição disciplinar por excelência, de fazer com que as crianças obedeçam ordens pontualmente e mantenham-se em seus lugares (talvez elas já nem saibam bem o que seja pontualmente
${ }^{3}$ É importante frisar que não estou afirmando que o trabalho fabril está desaparecendo, mas que está perdendo a importância que tinha na Modernidade e, ao mesmo tempo, se reorganizando. O trabalho fabril já não requer apenas os corpos treinados, mas cérebros capazes de comandar as novas máquinas. Como colocam Lazzarato e Negri (2001), a alma do operário deve descer ao chão de fábrica. 
ou o significado da expressão seus lugares...), sinaliza que possivelmente estejamos efetivamente passando para a sociedade sem disciplina de que nos fala Foucault ou, pelo menos, sem aquele modelo de disciplina que caracterizou a Modernidade. A horda dos que necessitam correção não para de crescer, abarrotando os serviços de psicopedagogia, incrementando o uso de fármacos e promovendo esforços sempre crescentes na tentativa de normalizar os anormais.

Ao mesmo tempo em que as escolas têm tido dificuldade para disciplinar seus alunos, por todos os lados ouvem-se vozes proclamando que ela deve mudar, que ela deve abandonar o "ensino tradicional” (que aqui identificamos com as chamadas pedagogias disciplinares). Observa-se hoje uma crescente pressão para que sejam adotados procedimentos pedagógicos que estariam fora da racionalidade disciplinar. As escolas, e também as instituições de ensino superior, vêm sendo bombardeadas por todos os lados para que transformem suas práticas: trabalhos acadêmicos, livros e revistas destinados aos professores; e reportagens midiáticas indicam, de modo quase unânime, que a educação só poderá melhorar se a rigidez dos sistemas disciplinares for substituída por desenhos curriculares e metodologias que priorizem uma aprendizagem mais autônoma e flexível, com ênfase nos interesses dos sujeitos. Temas como currículos orientados por competência, projetos de aprendizagem e interdisciplinaridade vão nessa direção.

Contudo, o enfraquecimento da disciplina não significa que se esteja abrindo mão de moralizar e governar os sujeitos, buscando conduzir suas condutas. De modo geral, quando se fala na atual crise da escola e se chamam especialistas e outras vozes para discuti-la, percebo que as soluções apontadas para as instituições educacionais vão no sentido de manterem uma forte ênfase na moralização dos educandos, ainda que com diferenças marcantes em relação à Modernidade. São outras formas de controle, que muitas vezes parecem afastar-se dos procedimentos disciplinares, tornando-se mais sutis e menos visíveis. Os corpos (e almas) atuais possivelmente não necessitem tanto obedecer ordens pontualmente, mas submeterem-se aos apelos da racionalidade atual, produzindo-se como sujeitos autônomos, pró-ativos e empreendedores. Essas são mudanças exigidas da escola, anunciadas e propaladas pela mídia, por ONGs, pelas políticas públicas.

Para melhor compreender a natureza das transformações nos processos de moralização mobilizados pela educação, é importante compreender um pouco melhor o uso que faço desse conceito. Segundo Foucault (2001a), toda moral envolve duas dimensões articuladas: os códigos de comportamento, identificados como tecnologias de dominação - ou seja, ações que atuam sobre as ações dos outros, por meio de estratégias que não são, necessariamente, coercitivas - e as formas de subjetivação, identificados como tecnologias do eu -ou seja, práticas que estabelecem procedimentos para cada um manter uma relação consigo mesmo. Em certos 
casos, a ênfase está no lado dos códigos, que são detalhados, capazes de prever um grande número de situações diversas. Já em outros, o que mais importa são as técnicas de subjetivação, a relação do ser-consigo. Quando a ênfase está nas formas de subjetivação, considera-se mais importante um permanente domínio do indivíduo sobre suas ações, pensamentos, comportamentos, sentimentos do que a observação do código de forma estrita. O código não é tão rígido ou tão detalhado, mas o trabalho do ser sobre si mesmo, produzindo-se como sujeito moral, passa a ser preponderante e demanda um maior esforço individual.

A moral da sociedade e da escola modernas privilegia o código. Na escola disciplinar, os alunos, submetidos ao olhar do professor, não devem cometer infrações ao regulamento estabelecido, sob pena de sanções. O trabalho sobre si constitui-se, principalmente, em desenvolver a obediência, conduzindo-se de acordo com os preceitos estabelecidos e bem definidos. Na racionalidade contemporânea, creio que a ênfase se desloca. Os códigos de conduta são cada vez mais difusos, fluidos, os regulamentos são atenuados e substituídos por regulações ${ }^{5}$ fluidas, cujas regras não estão definidas com tanta clareza.

Já não existem padrões únicos e os múltiplos padrões aceitáveis estão permanentemente se transformando. A instabilidade dos códigos inviabiliza que sejam enfatizados. Nesse contexto, os indivíduos para os quais são dirigidos os processos de moralização contemporâneos devem se dedicar a um permanente processo de subjetivação, impondo-se um continuado programa de atualizações que não pode ser descuidado sob pena de se verem jogados para o lado daquilo que Bauman (2005) chama de refugo humano. A governamentalidade que enfatizava a dominação na Modernidade, no meu entender, hoje estaria enfatizando as técnicas de si. De acordo com o que vem sendo preconizado para o sucesso das escolas, parece que se espera que esse deslocamento também se opere na educação, buscando-se outros modelos para produção do aluno contemporâneo que fortaleçam a importância das relações consigo mesmo.

Creio que aí se encontra um importante deslizamento dos procedimentos educacionais modernos para aqueles contemporâneos. Embora, em ambos os casos, deseje-se produzir o governamento e a moralização dos sujeitos, as ênfases mudam. Na Contemporaneidade, delega-se cada vez mais ao sujeito a tarefa de constituir-se e de gerir sua vida por meio de um trabalho sobre si mesmo. O governamento já não prioriza o corpo, suas ações e comportamentos, mas tem como alvo principal a alma, buscando regular o modo como cada um irá se constituir. Os regulamentos rígidos estariam cedendo espaço a orientações flexíveis e mutáveis.

Além desse deslizamento, parece-me também que a centralidade dos processos moralizadores presentes na escola básica moderna é ampliada, chegando hoje até o ensino superior. Na Modernidade, haveria uma cisão
${ }^{5}$ Na esteira de Foucault (2007), neste trabalho distingo regulamentos e regulações, tomando os primeiros como um conjunto de regras a serem obedecidas e que determinam o que cada um deve fazer e como deve se portar, enquanto as regulações são orientações gerais que não prescrevem ações, mas que estruturam um campo de possibilidades dentro do qual cada indivíduo toma suas decisões. As regulações seriam comparáveis às regras de um jogo, que colocam limites às ações dos jogadores, sem prescrevê-las. 
entre a formação dos operários e daqueles que viriam a desempenhar funções mais qualificadas. A disciplina, que era fortemente necessária para o chamado trabalhador braçal, estava presente na escola. Nas universidades, que deveriam produzir uma elite intelectual apta a desenvolver trabalhos especializados, o foco estava no conhecimento técnico (afinal, a disciplina já fora ensinada anteriormente).

Para o capitalismo pós-industrial já não interessa tanto trabalhadores com a disciplina da fábrica fordista, com seus gestos bem treinados e cronometrados. Os trabalhadores da era do trabalho imaterial devem ser flexíveis e capazes de exercer um controle sobre si constante, readaptando-se às novas normas com a mesma rapidez com que as fábricas se readaptam à fabricação de novos produtos. Já não podem contar com um olhar vigilante, que impõe ordens a serem seguidas, mas devem antecipar-se e criar suas próprias ordens para atingir as metas que lhes são impostas, como manda a cartilha da pró-atividade. E isso vale para todos os níveis hierárquicos da empresa, ainda que com matizes diferenciados. Governar as condutas dos sujeitos por meio de tecnologias de subjetivação, que passam pela alma para atingir o corpo, parece estar se tornando importante em todos os níveis educacionais, da educação infantil à universidade.

Parece-me que algumas práticas emergentes no final do século $\mathrm{XX}$ corroboram essas colocações. A Lei de Diretrizes e Base (LDB) e seus desdobramentos nas diretrizes curriculares, quando indicam a necessidade de construir currículos por competências - ou seja, que levem em conta não apenas o conhecimento e as aptidões técnicas, como também o desenvolvimento de atitudes -, sinalizam essa ênfase no governamento dos graduandos. Ou seja, as diretrizes curriculares deixam claro que as graduações hoje devem ter uma forte atuação não apenas na construção de um perfil técnico, como também (e, talvez, principalmente) na produção de um certo tipo de sujeito, com determinadas características que parecem variar muito pouco de um curso para outro. Assim, as diretrizes curriculares atribuem um papel moralizador ao ensino superior.

Outro indício desses novos processos moralizadores que se desenvolvem em todos os níveis é a ênfase dada ao "aprender a aprender” em diversos documentos e currículos, que desloca o foco da educação do conhecimento para o próprio processo de aprendizagem, incentivando o educando a fazer de si um sujeito que aprende. O “aprender a aprender” funciona, assim, como uma tecnologia do eu que orienta a relação do indivíduo consigo mesmo para a produção de um aprendiz permanente. Diversas outras práticas, surgidas nos últimos anos, que deslocam o foco da educação superior dos conhecimentos para a subjetivação poderiam ser lembradas, mas deixo para aprofundar essas questões em um outro momento. Gostaria de na continuidade tomar como objeto de análise uma prática que emergiu na última década e que vem se proliferando rapidamente, principalmente 
em cursos de graduação e pós-graduação lato sensu: a educação a distância mediada pela internet.

\section{Educação a Distância como estratégia de governamento}

A educação a distância, embora já exista no Brasil desde o século XIX, recebeu novo impulso na última década, ganhando reconhecimento e passando a ser largamente utilizada no ensino superior. A difusão da internet comercial produziu um meio para realizar essa modalidade educacional que, diferentemente daqueles utilizados anteriormente (correspondência, TV e rádio), permite uma ampla comunicação entre todos os participantes.

A EaD, muito frequentemente, é desenvolvida utilizando um site especialmente criado para esse fim. Esses sites, chamados de ambientes de aprendizagem, contam com diversos recursos, sendo os mais frequentes uma área para colocar arquivos com conteúdos e orientações sobre o curso, outra para os alunos colocarem arquivos com seus trabalhos e ferramentas para interatividade, como o chat e o fórum. Na maior parte das vezes, a única atividade síncrona do curso são os chats. As restantes podem ser realizadas quando o estudante desejar. Tanto nas atividades síncronas, quanto nas assíncronas, o estudante pode escolher de onde irá acessar o ambiente, não havendo restrições espaciais.

Pelo fato da EaD mediada pela internet tornar possível que os alunos estudem onde e quando for mais conveniente, liberando-os de horários rígidos e da necessidade de estarem presentes em uma dada instituição, essa modalidade educacional vem sendo tomada como uma prática educativa que daria uma maior liberdade aos sujeitos. Contudo, como mostrarei a seguir, as orientações que vêm sendo produzidas por pesquisadores e especialistas no campo da educação para a EaD estão constituindo-a como um processo educacional fortemente orientado para o governamento dos sujeitos. As análises que aqui desenvolvo estão baseadas em artigos publicados em periódicos nacionais, voltados para a temática do uso da tecnologia na educação ${ }^{6}$. A partir da leitura dos artigos, pude perceber um grande destaque dado ao controle das ações dos alunos pelo professor, bem como a estratégias para o desenvolvimento de autonomia e de controle de si, ou seja, estratégias para potencializar a capacidade de cada sujeito realizar o governo de si.

Através de uma transferência progressiva do controle das tarefas para o aluno, apoiada na retroalimentação proporcionada, num processo de avaliação contínua, estaremos contribuindo, não só com a construção do conhecimento em relação à utilização de técnicas e conceitos necessários, mas, sobretudo, para que os alunos se tornem cada vez mais autônomos e aprendam a aprender. (LIMA; SAUER, 2002, p. 41).

${ }^{6}$ As análises deste estudo têm por base 239 artigos publicados em periódicos nacionais sobre EaD, material empírico coletado e catalogado dentro de projeto de pesquisa da autora. 
Outro indício da ênfase no governamento dos alunos em EaD encontra-se no modo como os artigos apresentam o papel do professor nessa modalidade educacional, algumas vezes desdobrado em professor -aquele que elabora conteúdos e métodos- e tutor -aquele que trabalha diretamente com os alunos:

Merece destaque a mudança do papel do professor que, ao passar às tecnologias de informação a responsabilidade de "entregar" o conhecimento a quem aprende, libera-se para ser mais um guia do aluno, um "conselheiro”, um parceiro na procura da informação e da verdade. (OLIVEIRA; NOGUEIRA, 2002, p.96).

A função principal do tutor é facilitar o processo de ensino-aprendizagem e criar condições para que o aluno construa sua aprendizagem com autonomia. Portanto, não lhe cabe transmitir conteúdos (esta é a função do professor), mas, sim, reforçar o processo de auto-aprendizagem dos alunos. O tutor é o profissional responsável por orientar, acompanhar e fornecer apoio ao aluno. (PEREIRA; MOTTA; PAULA, 2003, p.104).

Ao longo dos artigos, passagens semelhantes às anteriores repetem-se dezenas de vezes, frisando que o professor já não tem como função principal transmitir o conhecimento. Parece, mesmo, que ele não já precisaria conhecer profundamente o conteúdo (no caso do tutor isso é reforçado pelo fato de esse ser, em geral, um sujeito com menor titulação do que o professor). Ele já não é o “detentor do conhecimento”, mas alguém que organiza uma aprendizagem coletiva, ou seja, que governa os alunos, orientando suas condutas para que se tornem sujeitos capazes de uma busca autônoma do conhecimento. Os professores e tutores na EaD necessitariam de mais saberes acerca de como transmitirem uma moral do que conhecimento.

Tudo isso aponta para uma ênfase nos processos de subjetivação nas práticas de educação a distância, visando transformar condutas, comportamentos e valores. A questão do governamento e da moralização dos sujeitos nesses documentos pode ser analisada sob diversos ângulos. Um dos aspectos que me parece mais recorrente e mais interessante de analisar seria o governamento por meio das disposições espaço-temporais, que consistiriam, conforme a opinião corrente, justamente a principal condição de uma suposta ampliação de liberdade dos indivíduos nos cursos a distância em relação aos presenciais.

Os conceitos existentes sobre a educação a distância indicam especialmente que esta pressupõe a autonomia do aluno, que irá organizar-se de acordo com suas possibilidades de tempo, espaço e ritmo de aprendizagem, contando, para isso, com diversos recursos didáticos. (PEREIRA; MOTTA; PAULA, 2003 p.103). 
$\mathrm{Na} \mathrm{EaD}$, os alunos são poupados da rígida grade de horários e dispensados da presença em um determinado local. Todavia, essa maior flexibilidade, que está sendo entendida como liberdade, exige uma contrapartida. A liberação do enclausuramento do corpo exige a intensificação da auto-regulação.

O ambiente, através das mensagens postadas, dos textos, das comunicações expressa um convite ao envolvimento e comprometimento do aluno com sua aprendizagem. $\mathrm{O}$ aluno é livre para interagir nos momentos que julga oportuno, numa linguagem livre e não por padrão de repostas ou interações. A elaboração pessoal, característica das mensagens dos alunos, é indicativo do desenvolvimento do que Piaget denomina de "autogoverno". O aluno toma a decisão de quando e como interagir e desta forma compromete-se com sua aprendizagem e com a aprendizagem do grupo, superando a submissão às regras externas impostas sobretudo pelo professor. (VALENTINI; FAGUNDES, 2001, p.114).

O excerto acima mostra como, ao saírem de cena as normas rígidas e pré-estabelecidas criadas pelo docente, cabe ao aluno definir o modus operandi. Dar ao aluno mais autonomia na escolha do modo como irá proceder é incumbi-lo de novas responsabilidades, ensinando-o a viver como um gestor de seus recursos e mostrando que, embora se possa decidir sobre os procedimentos, devemos nos submeter às regulações que se impõem ao corpo coletivo da população.

O desenclausuramento conduz a ações de controle a distância, utilizando equipamentos eletrônicos que são capazes de extrair verdades sobre as atividades dos sujeitos que nenhum professor conseguiria com seu olhar.

Atividades virtuais suportadas por ferramentas eletrônicas de gerenciamento, podem registrar, nos mínimos detalhes, todas as ações e reações (ou falta delas) de cada um dos alunos participantes. Essa base de dados, se devidamente garimpada (conceito também conhecido por data-mining) e tratada por programas de análise e visualização de dados, podem gerar informações, impossíveis de se obter em atividades presenciais convencionais. (TORI, 2002).

Essas transformações no modo de observar o aluno, passando da vigilância sobre o corpo para uma visibilidade ubíqua sobre sua produção, ressoam as palavras de Deleuze (1992, p.216), proferidas em entrevista concedida em 1990, em que fala de "uma terrível formação permanente, de um controle contínuo se exercendo sobre o operário-aluno ou sobre o executivo-universitário".

A passagem de um sistema regulamentado, com normas rígidas determinando o que deve ser feito e como, para um sistema regulado, que apenas coloca regras a serem observadas, deixando que cada um tome decisões autônomas, é o que se observa na passagem de uma educação 
fortemente disciplinar para as atuais configurações, que priorizam aquilo que Varela (1996) chama de pedagogias psicológicas.

Alguns autores [...] defendem as novas tecnologias em EAD como condição para uma aprendizagem flexível isto é: os estudantes aprendem como querem, quando querem e o que querem. Essa flexibilidade propõe novos papéis tanto aos professores quanto aos alunos e impõe a estes novas demandas como auto-iniciativa e auto-controle. (SUBTIL, 2002, p. 28).

A partir da leitura dos cursos Segurança, Território e População (FOUCAULT, 2006) e Nascimento da Biopolítica (FOUCAULT, 2007), ministrados no Collège de France nos anos de 1978 e 1979, respectivamente, podemos perceber conexões entre aquilo que expus anteriormente e a governamentalidade neoliberal ${ }^{7}$ que cada vez mais rege a organização social e política do Brasil e, também, de parte significativa de outros países. Conforme Foucault (2007), a empresa é o elemento organizador das sociedades neoliberais, sendo que cada um deve pensar em si mesmo como uma empresa a ser gerida. O princípio do neoliberalismo é a competição, que se estabelece não apenas entre instituições, mas também entre indivíduos. Cada um deve encarar sua vida como um empreendimento, mesmo nas esferas que não têm estrita ligação com a economia. Na racionalidade neoliberal, o mercado tende a recobrir a plenitude da vida. As avaliações sobre investimento e taxa de retorno não estariam restritas aos investimentos financeiros, mas a todo e qualquer investimento: de tempo, de afeto, de esforço. As fronteiras que separavam o espaço do mercado do espaço da vida estão se apagando. $\mathrm{E}$ a $\mathrm{EaD}$, com suas estratégias, contribui para a formação deste sujeito microempresa.

[O ambiente de aprendizagem] centra-se na capacidade de auto-gestão e motivação intrínseca do aluno, o que faz que predomine a autoaprendizagem, ou seja, o aluno é quem controla o processo de aprendizagem. (TIJIBOY; OTSUKA; SANTAROSA, 1998, p.28).

Trata-se de uma forma de ensino dirigida a uma população de jovens e adultos com suficiente maturidade para assumir seus estudos e administrar sua própria aprendizagem. Cabe, também, ao aluno a responsabilidade de estabelecer e perseguir seus próprios objetivos de aprendizagem, de administrar seu tempo para pesquisas, leituras, consultas à Internet e elaboração de tarefas. (MOULIN; PEREIRA; TRARBACH, 2004, p.27).

Desse modo, percebe-se que as estratégias educacionais contemporâneas, entre elas a $\mathrm{EaD}$, estão imbricadas com essa governamentalidade neoliberal, contribuindo para a produção de sujeitos que saibam manejar suas liberdades reguladas. Esses sujeitos mantêm uma outra relação com o espaço e o tempo diferente daquela dos sujeitos da sociedade disciplinar: espaço e tempo deixam de ter o sentido coletivizado que tinham então,
${ }^{7}$ É importante salientar que a noção de governamentalidade não se refere simplesmente a um modo de conduzir as questões do Estado, sendo bem mais abrangente. Quando me refiro a uma governamentalidade neoliberal, estou tratando de uma certa racionalidade que se instala na sociedade, constituindo formas de compreender o mundo, de estabelecer valores e de estabelecer comportamentos que se refletem também nas instâncias estatais. 
com usos determinados mais pelos imperativos sociais do que pelos desejos individuais, e passam a ser variáveis cada vez mais individualizadas a serem geridas pelos sujeitos. Esses sujeitos gestores da própria vida são talhados para um trabalho que tem como referência o trabalho imaterial. Sujeitos que já não se comportam como trabalhadores disciplinados, mas como gerentes da Você S.A.

Retomando a análise dos artigos, observo, ainda, que o desenclausuramento potencializa uma saturação na captura dos tempos individuais. A comunicação via web faz com que já não exista um horário determinado para o contato entre professor e alunos, apagando os limites temporais que eram impostos na educação presencial. Ao minimizar os tempos coletivos e estabelecer a necessidade de escolha de horários para dedicar-se às tarefas educacionais, institui-se que todo o tempo poderia ser utilizado com esse fim.

Não há portanto limite para dúvidas e participações dos alunos, que também perdem a timidez e ficam muito mais exigentes quanto ao tempo de resposta. (TORI, 2002).

Por último, diferentemente do presencial, o ensino na modalidade a distância promovido por meio desta topologia, atende o aluno distante 24 horas por dia. (MEDEIROS ET AL., 2001, p.13).

O uso de recursos de comunicação via web faz com que já não exista um horário determinado para o contato entre professor e alunos, apagando os limites temporais que eram impostos na educação presencial. O tempo da sala de aula entra numa expansão virtualmente ilimitada. A EaD apresenta potencial para capturar todo o tempo dos sujeitos, sejam eles professores ou alunos. Os cursos on-line acabaram com os horários para dar lugar a uma atividade flexível e continuada. A liberdade de escolha dos momentos que serão dedicados ao estudo é paga com uma amplificação das obrigações mútuas. O fluxo de comunicação entre professor e alunos torna-se potencialmente ininterrupto. Percebo essa comunicação sem limites não somente como um recurso de aprendizagem dos conhecimentos, mas como um instrumento de controle que ensina a estar permanentemente comprometido e a exercer um governamento sobre si que torne eficiente o gerenciamento do seu tempo. Hoje, estar sempre em contato parece ser muito mais importante do que exercer um controle microfísico sobre o corpo.

Uma das [vantagens] mais indicadas pelos docentes foi a possibilidade de ampliação dos canais de comunicação entre o professor e seus alunos; por exemplo, caso houvesse necessidade de dar algum aviso aos alunos como de mudança na programação ou mesmo disponibilizar uma proposta de atividade de trabalho, tanto professores quanto alunos contavam com um ponto de contato para além dos limites de tempo e do espaço imposto pelo modelo de ensino presencial. (VARELLA; VERMELHO; SILVA, 2001, p.41). 
A adoção de ambientes de educação a distância como recursos complementares para cursos que se desenvolvem na forma presencial é mais um indício desse entendimento de que seria vantajoso intensificar o controle dos alunos por meio de uma maior captura do seu tempo e da intensificação da comunicação entre as partes.

Ainda que [os ambientes de aprendizagem] tenham sido inicialmente desenvolvidos para cursos não-presenciais, estes softwares são utilizados como ferramenta de apoio em cursos presenciais. (TANNOUS; RODRIGUES, 2002).

Esse comprometimento permanente produz saberes que vão além dos conteúdos do curso. Professores e alunos aprendem a regular seu tempo de trabalho e a imporem para si rotinas que incluem o acesso sistemático aos ambientes informatizados nos quais se estabelece a comunicação, deixando gradativamente de perceber uma divisão entre a vida pública e a vida privada. A possibilidade de contato contínuo não apenas intensifica a comunicação, como também constitui uma estratégia de controle mútuo permanente. Para criar novos espaços de liberdade, talvez seja necessário "criar vacúolos de não-comunicação, interruptores, para escapar ao controle” (DELEUZE, 1992, p.217).

\section{Algumas palavras para finalizar}

Neste artigo, procurei mostrar como as práticas educacionais contemporâneas, entre elas a EaD, parecem cada vez mais enfatizar o governamento dos sujeitos por meio de estratégias que orientam os processos de subjetivação, com especial ênfase nas transformações dos usos espaço-temporais. Produzir condutas cada vez mais a partir de um quadro de normas gerais reguladoras, onde cada um deve ter autonomia nas suas decisões, empalidecendo o modelo moderno de intensa regulamentação, que determinava o que cada um deveria fazer. Podemos entender esse processo de regulação das condutas como uma normalização que já não tem como prioridade comportamentos e valores pré-determinados, mas a aprendizagem de um modo de gestão de si. O governamento do sujeito contemporâneo estaria sendo constituído principalmente por meio das tecnologias do eu, práticas do ser-consigo, que necessitam ser permanentemente exercitadas para acompanhar os flutuantes modelos que permitem manter distância dos guetos repletos de um supranumerário descartável e descartado. Frente a normas instáveis e voláteis, a normalização estaria mais relacionada aos modos de subjetivação do que à produção de uma subjetividade dada. Hoje, o que parece possível ensinar aos sujeitos não são padrões de comportamento, valores e saberes, mas a estarem frequentemente se reconstituindo dentro de novos modelos. 
Na Modernidade, a disciplina funcionava como um molde da subjetividade. Os controles atuais funcionam como modulações, formas autodeformantes em constante mudança. "O homem da disciplina era um produtor descontínuo de energia, mas o homem do controle é antes ondulatório” (DELEUZE, 1992, p.223). A educação contemporânea, em geral, e a EaD, em particular, estão imbricadas com processos de governamento capazes de produzir esse homem ondulatório de que nos fala Deleuze.

\section{Referências}

BAUMAN, Zygmunt. Vidas desperdiçadas. Rio de Janeiro: Jorge Zahar, 2005.

DELEUZE, Gilles. Conversações. Rio de Janeiro: Ed. 34, 1992.

FOUCAULT, Michel. O Sujeito e o poder. In: RABINOW, Paul; DREYFUS, Hubert. Michel Foucault - uma trajetória filosófica. Rio de Janeiro: Forense Universitária, 1995. p.231-249.

FOUCAULT, Michel. Vigiar e punir. Petrópolis, RJ: Vozes, 1999.

FOUCAULT, Michel. Verdade e Poder. In: FOUCAULT, Michel. Microfísica do poder. Rio de Janeiro: Graal, 2000. p.1-14.

FOUCAULT, Michel. La societé disciplinaire en crise. In: FOUCAULT, Michel. Dits et écrits III. Paris: Gallimard, 2001. p. 532-533.

FOUCAULT, Michel. História da sexualidade, v.2 - o uso dos prazeres. Rio de Janeiro: Graal, 2001a.

FOUCAULT, Michel. Em defesa da sociedade. São Paulo: Martins Fontes, 2002.

FOUCAULT, Michel. O filósofo mascarado. In: FOUCAULT, Michel. Ditos e escritos II. Rio de Janeiro: Forense Universitária, 2005.

FOUCAULT, Michel. Seguridad, território, población. Buenos Aires: Fondo de Cultura Economica, 2006.

FOUCAULT, Michel. Nacimiento de la biopolitica. Buenos Aires: Fondo de Cultura Economica, 2007.

GALVÃO, Alexander; SILVA, Gerardo; COCCO, Giuseppe (orgs.). Capitalismo cognitivo. Rio de Janeiro: DP\&A, 2003.

HARDT, Michael; NEGRI, Antonio. Império. Rio de Janeiro: Record, 2002.

HARDT, Michael; NEGRI, Antonio. Multidão. Rio de Janeiro: Record, 2005.

HARVEY, David. Condição pós-moderna. São Paulo: Loyola, 2001. 
KANT, Immanuel. Sobre a pedagogia. Piracicaba: Unimep, 1996.

LAZZARATO, Maurizio; NEGRI, Antonio. Trabalho imaterial e subjetividade. In: LAZZARATO, Maurizio; NEGRI, Antonio. Trabalho imaterial. Rio de Janeiro: DP\&A, 2001. p.25-42.

LIMA, Isolda Giani; SAUER, Laurete Zanol. Ambientes Telemáticos no Processo de Ensino-Aprendizagem de Matemática. Informática na Educação: teoria \& prática, v5/n2. nov. 2002. p.31-42.

MEDEIROS, Gilbeto et al. Um cenário educacional para a PUCRS Virtual. Colabor@, Curitiba, v.1, n.1, p.12-17, ago. 2001. Disponível em: <http:// www.ricesu.com.br/colabora/n1/ index1.htm>. Acesso em: 19 jun. 2006.

MOULIN, Nelly; PEREIRA, Vilme; TRARBACH, Maria Aparecida. Formação do tutor para Educação a Distância. Tecnologia Educacional, Rio de Janeiro, v.31, n.163/166, p.25-36, set. 2004.

NIETZSCHE, Friedrich. Ecce homo: como alguém se torna o que é. São Paulo: Companhia das Letras, 1995.

OLIVEIRA, Eloiza; NOGUEIRA, Mário Lúcio. Educação a distância e formação de professores: desafios e perspectivas. Tecnologia Educacional, Rio de Janeiro, v.31, n.157/158, p.95-103, abr./set. 2002.

PEREIRA, Ana Maria; MOTTA, Neide; PAULA, Viviane de. As atividades do tutor no curso de Pedagogia na modalidade a distância da Coordenação de Educação a Distância da UDESC. Tecnologia Educacional, Rio de Janeiro, v.31, n.161/162, p.101-110, abr./set. 2003.

POL-DROIT, Roger. Michel Foucault - entrevistas. Rio de Janeiro: Graal, 2006.

SARAIVA, Karla. Educação a distância: outros tempos, outros espaços. Ponta Grossa (PR): UEPG, 2010.

SUBTIL, Maria José. Considerações gerais sobre a Educação a Distância a partir da perspectiva de alguns autores. Informática na Educação: teoria \& prática, Porto Alegre, v.5, n.1, p.25-30, mar. 2002.

TANNOUS, Katia; RODRIGUES, Sueli. Aplicación de Herramienta de Educación a Distancia como Soporte Didáctico a la Enseñanza en Ingeniería Química. Revista Brasileira de Aprendizagem Aberta e a Distância, São Paulo, v.1, n.2, dez. 2002. Disponível em: <http://www. abed.org.br/publique/cgi/cgilua.exe/sys/start.htm?UserActive Template=1 por\&infoid=640\&sid=131 $>$. Acesso em: 22 jun. 2006.

TIJIBOY, Ana Vilma, OTSUKA, Joice e SANTAROSA, Lucila. "Navegando pelo mundo": ambiente de aprendizagem telemático interdisciplinar. Informática na Educação: teoria \& prática, Porto Alegre, v.1, n.1, p.25-42, 1998. 
TORI, Romero. A Distância que Aproxima. Revista Brasileira de Aprendizagem Aberta e a Distância, São Paulo, v.1, n.2, dez. 2002. Disponível em: <http://www.abed.org.br/publique/cgi/cgilua.exe/sys/start. htm? UserActiveTemplate=1por\&infoid=640\&sid=131>. Acesso em: 16 out. 2005.

TRENTIN, Marco Antônio; TAROUCO, Liane M. R. Proposta de utilização de um laboratório virtual de física na melhoria do processo de ensino e aprendizagem. Informática na Educação: teoria \& prática, Porto Alegre, v.5, n.2, p.54-60, set. 2002.

VALENTINI, Carla; FAGUNDES, Léa. Ambiente virtuais deaprendizagem: sistema, organização e interação. Informática na Educação: teoria \& prática, Porto Alegre, v.4, n.2, p.109-117, dez. 2001.

VARELA, Julia; ALVAREZ-URIA, Fernando. A maquinaria escolar. Teoria \& Educação. Porto Alegre: Pannonica, n. 6, 1992. p.68-95.

VARELA, Julia. Categorais Espaço-temporais e socialização escolar. In: COSTA, Marisa V. (org.). Escola Básica na virada do século. Porto Alegre: UFRGS, 1996. p.37-56.

VARELLA, Péricles; VERMELHO, Sonia Cristina; SILVA, Ana Carolina da. A experiência da UCPR na implantação das tecnologias de informação e comunicação no ensino superior. Colabor@, Curitiba, v.1, n.1, p.3745, ago. 2001. Disponível em: <http://www.ricesu.com.br/ colabora/n1/ index1.htm>. Acesso em: 16 jun. 2006.

VEEN, Win; VRAKKING, Ben. Homo zappiens: educando na era digital. Porto Alegre: Artmed, 2009.

VEIGA-NETO, Alfredo. De geometrias, currículos e diferenças. Educação \& Sociedade, Campinas, n. 79, p.163-186, ago. 2002a.

VEIGA-NETO, Alfredo. Coisas de Governo. In: RAGO, Margareth; ORLANDI, Luiz; VEIGA-NETO, Alfredo. Imagens de Foucault e Deleuze. Rio de Janeiro: DP\&A, 2002b.

VEIGA-NETO, Alfredo. Foucault e a Educação. Belo Horizonte: Autêntica, 2003.

Recebido em: 15/05/2013

Aprovado em: 22/07/2013 